\title{
CARDIO-PROTECTIVE ROLE OF HEAT SHOCK PROTEIN 70 (HSP 70) AMONG HEAT-EXPOSED WORKERS
}

\author{
By \\ Farahat $\mathrm{SA}^{1}$, Samir AM ${ }^{1}$, Shaker DA ${ }^{1}$, Rashed $\mathrm{LA}^{2}$ \\ Dep. Industrial Med. And Occupational.Diseases. \\ Dep. Medical Biochemistry, Faculty of Medicine , Cairo university
}

\begin{abstract}
:
Aim: This work aimed at studying the prevalence of ischemic heart diseases (IHD) among heat-exposed workers and the extent of having the high risk factors particularly dyslipidemia and hypertension among this group of workers. Besides, the cardioprotective role of heat shock protein 70 (HSP 70), as a molecular heat exposure biomarker, was clarified. Subjects: The study subjects consisted of a heat-exposed 29 bakers group employed in 10 manual bakeries and a matched heat unexposed group ( $\mathrm{n}=$ 29). Methods: Every individual underwent occupational and clinical history taking, resting electrocardiogram (ECG), estimation of serum lipid profile parameters, $\{$ total cholesterol (TC), high density lipoprotein (HDL-C), TC/HDL-C ratio, low density lipoprotein (LDL-C), triglycerides (TG)\} and heat shock protein 70 (HSP70). Results: Analysis of history showed significantly higher prevalence of heat cramps (27.5\%) and heat rash (34.5\%) among the heat-exposed group. Resting ECG revealed ischemic manifestations in $20.6 \%$ of the heat-exposed workers versus $13.7 \%$ of their controls $(\mathrm{P}<0.05)$. Marked significant increase in all lipid profile parameters was detected in the heat-exposed individuals with positive correlation with duration of work. The HSP 70 level was 2 times higher among the heat-exposed group. The individuals having ischemic manifestations had lower HSP70 level. Conclusion: Working in hot environments can induce unfavorable increase in blood lipids which predisposes workers to IHD. As HSP 70 which is known to have a cardio-protective role declines with age with consequent diminishing of its cardio-protective role, elderly workers
\end{abstract}


exposed to heat would have higher incidence of IHD which necessitates avoidance of working under hot conditions.

Key Words: Heat, Heat illness, Heat shock protein 70, Ischemic heart diseases, , Dyslipidemia, ECG.

\section{Introduction}

Heat has been on record as a hazard to man since biblical times. Operations involving high air temperatures, radiant heat sources, high humidity, direct physical contact with hot objects, or strenuous physical activities have a high potential for inducing heat stress in employees engaged in such operations (Srivastava et al, 2000).

When a worker is exposed to high levels of heat and humidity, the body reacts by certain physiological responses. Body response includes increasing the heart rate and stroke volume with subsequent increase in cardiac output (Rodahl, 2003). A significant amount of blood flow will be diverted to the peripheral circulation to dissipate heat to the surrounding environment. The circulating blood diverted to the periphery reduces the amount of oxygenated blood going to the metabolically active muscles thus decreasing the work capacity of the worker. Internal heat in the peripheral circulation is lost to the environment by way of active sweating in an attempt to maintain thermal homeostasis, which leads to progressive water and electrolyte loss over time ( Bates and Miller, 2008). The process of acclimatization (AC) is made to adapt the body to heat exposure. Therefore, AC ends up with reduction in sodium loss in sweat, reduction in lactate accumulation in blood and muscles and reducing the increased heart rate and stroke volume. When the environmental and metabolic heat loads exceed the ability of the body to dissipate heat, various types of heat illnesses may develop (Tanaka,2007).

Recently, excessive expression of heat shock protein 70 (HSP70), was considered as part of physiological responses to heat exposure (Yaun et al., 2005). Heat shock proteins (HSPs) constitute a large family of proteins that aid in a cell's response to acute stress. They are multigene families that range in molecular size from 10 to $150 \mathrm{kDa}$ and are found in all major cellular compartments (luc et al.,2001). According to molecular weight, they are divided into the following families: HSP10, small HSPs, HSP40, HSP60, HSP70, HSP90, and HSP110. The HSP70 family has been shown to protect cells against apoptosis 
induced by thermal stress, oxidative stress, radiation, and chemical toxins ( Lepore et al., 2001).

Kumar et al., (2003) reported marked increase in the level of HSP 70 in persons exposed to overheat and this increase was known to be correlated to stress tolerance and accumulative circulatory strain. Moreover, the authors discussed the usefulness of using the HSP 70 as a molecular marker of heat stress. The cardioprotective role of HSP 70 was documented in many studies as it may mitigate the stress induced cardiomyocyte injury. Besides, the elevated HSP 70 correlated significantly with decreased ECG abnormalities ( Zhao et al., 2007).

Nowadays, a growing number of studies is reporting about a significantly higher mortality from cardiovascular disease ( CVD) with particular increase in ischemic heart disease (IHD) among workers in hot environments (Wild et al., 1995, Vangelova and Deyanov,1999, Nawrot et al.,2005)

The aim of the current work was to study the prevalence of IHD among heat-exposed workers and investigate the presence of dyslipidemia and hypertension as most important risk factors in IHD among this group of workers. Estimation of HSP 70 was done to clarify its protective role.

\section{Subjects \& Methods}

\section{Study population}

A cross-sectional study was carried out among a group of bread bakers employed in 10 manual bakeries distributed in different regions in Cairo governorate (total no.= 34). According to our selection criteria, only those who had $>2$ years duration of employment were invited to join our study ( no.=32). Unfortunately, 3 workers refused to join the study so the exposed group included 29 male workers.

The control subjects, a total of 29 individual were chosen from workers and food sellers present in the residential areas of the bakeries. They were matching with the exposed subjects in sex, age, smoking index, past history of diabetes and socioeconomic standard but had no history of working in hot environment.

\section{Methods}

Every individual in the study was subjected to detailed occupational history, clinical history taking with emphasis on heat illness manifestations ( heat cramps, heat rash, heat stroke), renal disorders (concentrated urine, repeated dysuria, renal stones), cardiovascular manifestations of ischemic heart disease ( chest pain characteristic of coronary insufficiency, dyspnea, palpitation) and past history 
of hypertension and diabetes. Clinical examination including measurement of blood pressure by $\mathrm{Hg}$ sphygmomanometer and heart rate was done.

Resting ECG recording with significant depression of ST segment and T- wave inversion or falttening was considered as sign of ischemic heart diseases. ST segment depression was considered significant if the ST segment was at least one box below baseline, as measured two small boxes after the end of the QRS. Also other abnormalities in the ECG were considered.

\section{Blood analysis for}

a. Lipid profile after overnight fasting( total blood cholesterol TC, high density lipoprotein cholestrol HDL-C, low density lipoprotein cholesterol LDL-C, and triglycerides TG, TC/HDL-C ratio). They were measured using the commercially available kit. The results were expressed in $\mathrm{mg} / \mathrm{dl}$.

b. Fasting blood sugar ( workers refused to make $2 \mathrm{~h}$ pp blood sugar)

c. Heat shock protein 70 (HSP 70) was estimated by using a specific sandwich enzyme-linked immunoassay (ELISA) kit supplied by Stressgen Biotechnologies. Results were expressed in $\mathrm{ng} / \mathrm{dl}$.

\section{Statistical Analysis}

Results were evaluated for each group. Data were compared using Student t-test. Qualitative data for ECG changes, heat illness and urinary disorders were compared using chi square test. ANOVA test was used to compare exposed subgroups and control subjects. Pearson correlation test was used to test the correlation between different variables among the exposed groups. The statistical significance was defined as $\mathrm{P}$ value $<0.05$. Computer based statistical package for social sciences (SPSS) for windows 9.1 program was used.

\section{Results}

This study was conducted on 58 male workers divided into a heat-exposed bakery workers $(n=29)$ and a matched control group $(n=29)$. The age range of the individuals in the exposed group was (28-57 years) with a mean value of $43.31 \pm 7.12$ years showing no statistically significant difference when compared with the control group (range= $30-55$ years, mean $=43.03 \pm 6.92)$. The mean duration of working years of the exposed personnel was 18 17.54 years. Smoking index estimation showed no difference statistically between the groups

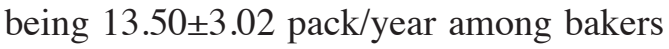
and 12.04 \pm 2.02 among their controls. 
The frequency distribution of symptoms suggestive of heat illness ( table 1) showed significantly, higher prevalence of heat cramps and heat rash in the heatexposed group $(\mathrm{P}<0.05)$. Muscle cramps were expressed as painful uncontrolled muscle contractions usually occurring in the gastrocnemius [calf muscle] or in the thigh area.

Having little amount of concentrated dark urine was reported by a large sector of heat-exposed workers and this complaint was associated in many cases with repeated urinary infections expressed by having dysuria and frequency of micturation. Besides, history of renal stones with or without treatment was reported by a significantly higher number of exposed workers compared to controls ( table 1).

Studying resting ECG recordings revealed significantly higher percentage of ischemic manifestations among heatexposed workers than in their controls (table $2 \mathrm{P}<0.05$ ). Tall peaked $\mathrm{T}$ - wave was found in 6 heat-exposed workers versus none in the control group. Peaked T- wave was accompanied with relatively small $\mathrm{P}$ wave and was detected throughout all leads of the ECG.

Analysis of lipid profile results, showed significantly higher percentage of heatexposed bakers who had dyslipidemia (table $2 \mathrm{P}<0.05$ ). However, mean values of lipid profile parameters were significantly higher among heat-exposed group as compared to their controls ( table $3 \mathrm{P}<0.05$ ). This increase in lipid profile parameters was positively correlated with duration of exposure ( table $4 \mathrm{P}<0.05$ ).

As regards blood pressure measurements, lower mean values of SBP and DBP were detected among heat-exposed group but the difference was significant only for SBP ( table 3). HSP 70 mean value was 2-folds higher among the heat-exposed group with highly significant difference (table $3 \quad \mathrm{P}<0.000$ ). However, expression of HSP 70 was negatively correlated with age $(r=-0.031)$ but did not reach the level of significance $(\mathrm{P}>0.05$ table 4$)$.

According to the detected ischemic manifestations in ECG recordings, studied groups were subdivided as shown in table 5. Analysis of variance (ANOVA) between subgroups revealed significantly higher mean levels of lipid profile parameters and lower HSP70 among heat-exposed workers having ECG ischemic manifestations. Age of subjects having ischemic heart disease in heat-exposed and the control groups revealed no statistical difference of significance by using Post Hoc test. 
Table (1): Frequency distribution of heat illness manifestations among heat-exposed bakers $(n=29)$ and control group $(n=29)$.

\begin{tabular}{|lccccc|}
\hline Heat illness & \multicolumn{3}{c}{ Heat-exposed } & \multicolumn{3}{c|}{ Control group } & \multirow{2}{*}{$\begin{array}{l}\text { groupN=29 } \\
\text { N }\end{array}$} & \% & N & \% & \\
\hline Heat rash & 10 & 34.5 & 0 & 0 & $<0.001^{*}$ \\
\hline Heat cramps & 8 & 27.5 & 0 & 0 & $<0.001^{*}$ \\
\hline Renal disorders & 19 & 51 & 7 & 24 & $<0.05^{*}$ \\
\hline
\end{tabular}

*statistically significant

Table (2): Frequency distribution of abnormalities in resting ECG findings and abnormal lipid profile parameters (total blood cholesterol TC, high density lipoprotein cholesterol HDL-C, low density lipoprotein cholesterol LDL-C, and triglycerides TG in $\mathrm{mg} / \mathrm{dl}$ and TC/HDL-C ratio subtypes among heat-exposed bakers ( $n=29)$ and control group $(n=29)$.

\begin{tabular}{|c|c|c|c|c|}
\hline & \multicolumn{2}{|c|}{$\begin{array}{l}\text { Heat-exposed group } \\
\qquad \mathbf{N}=29\end{array}$} & \multicolumn{2}{|c|}{$\begin{array}{c}\text { Control group } \\
\quad \mathrm{N}=\mathbf{2 9}\end{array}$} \\
\hline & $\mathbf{N}$ & $\%$ & $\mathbf{N}$ & \\
\hline \multicolumn{5}{|l|}{ ECG Findings } \\
\hline IHD & 6 & 20.6 & 4 & 13.7 \\
\hline Tall T- wave & 6 & 20.6 & & \\
\hline \multicolumn{5}{|l|}{ Dyslipidemia } \\
\hline $\mathrm{TC}>200 \mathrm{mg} / \mathrm{dl}$ & 18 & 58 & 5 & 17 \\
\hline HDL-C $<60 \mathrm{mg} / \mathrm{dl}$ & 8 & 27 & 12 & 41 \\
\hline LDL-C>160 mg/dl & 13 & 45 & 2 & 6 \\
\hline TC/HDL-C $>3$ & 18 & 58 & 6 & 20.5 \\
\hline $\mathrm{TG}>150 \mathrm{mg} / \mathrm{dl}$ & 7 & 24 & 4 & 14 \\
\hline $\mathbf{P}$ & \multicolumn{4}{|c|}{$<0.05$} \\
\hline
\end{tabular}


Table (3): Mean \pm SD of systolic blood pressure (SBP $\mathrm{mmHg}$ ), diastolic blood pressure (DBP mm Hg), heart rate (HR), lipid profile parameters (total blood cholesterol TC, high density lipoprotein cholesterol HDL-C, low density lipoprotein cholesterol LDL-C, and triglycerides TG in mg/dl and TC/HDL-C ratio) and heat shock protein 70 (HSP 70 in ng/dl) among heat-exposed group (no=29) and the control group $($ no $=29)$.

\begin{tabular}{|c|c|c|c|}
\hline Variables & $\begin{array}{c}\text { Exposed group } \\
\qquad=29\end{array}$ & $\begin{array}{c}\text { Control group } \\
\qquad \mathrm{N}=29\end{array}$ & $\mathbf{P}$ \\
\hline $\mathrm{SBP}(\mathrm{mm} \mathrm{Hg})$ & $114.65 \pm 12.81$ & $130.34 \pm 12.82$ & $<0.05^{*}$ \\
\hline DBP ( mm Hg) & $73.96 \pm 9.48$ & $74.16 \pm 9.38$ & $>0.05$ \\
\hline $\mathrm{TC}(\mathrm{mg} / \mathrm{dl})$ & $232.6 \pm 33.15$ & $173.86 \pm 18.85$ & $<0.05^{*}$ \\
\hline HDL-C(mg/dl) & $64.17 \pm 12.16$ & $58.57 \pm 12.52$ & $<0.05^{*}$ \\
\hline LDL-C(mg/dl) & $119.95 \pm 22.89$ & $117.2 \pm 14.47$ & $<0.05^{*}$ \\
\hline TC/HDL-C & $3.7 \pm 0.8$ & $3.1 \pm 0.83$ & $<0.05^{*}$ \\
\hline TG (mg/dl) & $120.35 \pm 20.37$ & $102.08 \pm \pm 16.83$ & $<0.05^{*}$ \\
\hline HSP70(ng/dl) & $51.7 \pm 14.38$ & $26.88 \pm 6.42$ & $<0.001 * *$ \\
\hline
\end{tabular}

* statistically significant

** statistically highly significant

Table (4): Correlation between age and duration of work with some lipid profile parameters and HSP 70 in the heat-exposed workers.

\begin{tabular}{|l|l|c|c|c|c|}
\hline & & TC & HDL-C & TG & HSP70 \\
\hline \multirow{2}{*}{ Age } & $\mathrm{r}=$ & 0.876 & -0.002 & 0.487 & -0.031 \\
& $\mathrm{p}$ & $<0.05$ & $\mathrm{n} . \mathrm{s}$ & $<0.05$ & $\mathrm{n} . \mathrm{s}$ \\
\hline \multirow{2}{*}{ Duration } & $\mathrm{r}=$ & 0.638 & -0.65 & 0.449 & \\
& $\mathrm{p}$ & $<0.05$ & $<0.05$ & $<0.05$ & ----------- \\
\hline
\end{tabular}


Table (5): ANOVA test between age, lipid profile parameters and HSP70 in groups having resting ECG evidences of IHD in both heat-exposed and control subgroups

\begin{tabular}{|l|c|c|c|c|c|}
\hline & $\begin{array}{c}\text { Heat-exposed } \\
\text { with IHD } \\
\mathbf{N = 6}\end{array}$ & $\begin{array}{c}\text { Heat-exposed } \\
\text { without IHD } \\
\mathbf{N = 2 3}\end{array}$ & $\begin{array}{c}\text { Control } \\
\text { with IHD } \\
\mathbf{N = 4}\end{array}$ & $\begin{array}{c}\text { Control } \\
\text { without IHD } \\
\mathbf{N = 2 5}\end{array}$ & P \\
\hline Age & $51 \pm 5.05$ & $41.30 \pm 6.2$ & $47.25 \pm 8.57$ & $42.36 \pm 6.58$ & $<0.05^{*}$ \\
\hline $\mathrm{TC}(\mathrm{mg} / \mathrm{dl})$ & $254.46 \pm 38.71$ & $226.83 \pm 29.89$ & $174.7 \pm 19.48$ & $173.73 \pm 19.16$ & $<0.05^{*}$ \\
\hline HDLC(mg/dl) & $63.23 \pm 8.89$ & $64.42 \pm 13.04$ & $53.72 \pm 4.37$ & $59.35 \pm 13.27$ & $\mathrm{n} . \mathrm{s}$ \\
\hline LDL-C(mg/dl) & $141.28 \pm 16.24$ & $124.06 \pm 24.76$ & $111.80 \pm 11.14$ & $118.11 \pm 14.93$ & $\mathrm{n} . \mathrm{s}$ \\
\hline TC/HDL-C & $4.0 \pm 0.87$ & $3.65 \pm 0.83$ & $3.28 \pm 0.57$ & $3.0 \pm 0.87$ & $<0.05^{*}$ \\
\hline $\mathrm{TG}(\mathrm{mg} / \mathrm{dl})$ & $138.38 \pm 29.83$ & $115.64 \pm 14.64$ & $101.9 \pm 18.68$ & $102.11 \pm 16.94$ & $<0.05^{*}$ \\
\hline HSP70 (ng/dl) & $45.66 \pm 12.08$ & $52.46 \pm 12.62$ & $26.65 \pm 10.08$ & $27.18 \pm 5.94$ & $<0.05^{*}$ \\
\hline
\end{tabular}

*statistically significant

\section{Discussion}

Heat stress is still one of the neglected occupational hazards in the tropical countries. It represents a major factor which may have negative impact on workers' efficiency and consequently on reproduction (Epstein and Moran,2006).

Unfortunately, in the current study we could not estimate the wet-bulbglobe temperature (WBGT) which is the common thermal index used to determine the environmental thermal load. However, a similar Egyptian study conducted by ElSaid et al., (2003) in some manual and semi-automatic bakeries reported higher heat exposure and humidity in the manual type of bakeries. In addition, the high prevalence of heat cramps (27.5\%) and heat rash $(34.5 \%)$ among heat-exposed workers in our study reveals that they experienced a certain degree of thermal overload. Similar high prevalence of heat cramps (30\%) was reported by Gomes et al., (2002) among workers in hot environment. Occurrence of heat cramps can be a reflection of water 
and electrolyte imbalance that results from excessive loss of water and sodium in sweat without adequate replacement of dietary sodium ( Awahl et al., 2000). Regarding heat rash, lack of personal hygiene blocks the sweat gland ducts so the sweat is forces out across the wall of the sweat duct into the subcutaneous tissue resulting in red rash with compromise in thermoregulation (Hancock and Vasmatzidis, 2003).

In the current study, $51 \%$ of heat-exposed workers reported having manifestations of urinary and renal disorders. Having little amount of concentrated, dark colored urine confirms a state of chronic dehydration that is experienced by heat-exposed workers and explains the higher frequency of urinary infections and renal stones as dehydration represents a real lithogenic risk factor (Brake and Bates, 2003).

In ECG tracing, T- wave abnormalities can provide added evidence to support clinical diagnosis. However, the T- wave must be considered along with QRS and ST segment abnormalities. When typical tall, peaked T- waves are seen only within a specific set of cardiac leads, this suggests impending infarction. In this condition, tall Ts are due to potassium leak through damaged membranes in the area of the infarct. If the tall $\mathrm{T}$ - waves are seen throughout the ECG, general hyperkalemia is present (Miranda et al., 1991) which is most probably the cause of presence of augmented T- wave among $20.6 \%$ of our exposed workers. Hyperkalemia can be attributed to excessive loss of sodium chloride in the sweat leading to lack of sodium ions in distal tubules of the kidney to exchange with potassium ions ( Lim et al., 1996). Similar higher prevalence of hyper acute T- wave was reported in heatexposed workers in a study conducted by El-Safty et al., (2008)

Until recently, heat shock proteins (HSPs) were mostly regarded as intracellular molecules that mediate a range of essential housekeeping and cytoprotective functions. However, interest in their role as intercellular signaling molecules has been fuelled by the observation that these molecules can be released and are present in the extracellular environment under physiological conditions (Ghayour-Mobarhan et al.,2005). HSP70 is the most intensively studied group of the HSPs because it is induced in stressed cells and is thought to represent a basic feature of the ability of cells to cope with adverse conditions and contributes to thermotolerance. ((Zhoa et al.,2007).

Although HSPs are largely intracellular molecules, extracellular over-expression 
of HSP 70 is considered as a part of physiological thermotolerance and a mediator of acclimatization (Steinmann and Bornman, 1996). In our study, the mean level of HSP 70 among the heat-exposed workers was about 2-fold its level in the control subjects $(51.7 \pm 14.38,26.88 \pm 6.42$ respectively) $(\mathrm{P}<0.001$ table 3$)$ which was similarly reported by Kumar et al., (2003) who found significant induction of HSP70 in response to heat exposure.

Analysis of symptoms suggestive of IHD among the study population was positive for only 1 case among the exposed and 2 among the controls. However, according to Miranda et al., (1991), the occurrence of ST-segment depression and $\mathrm{T}$-wave inversion in the resting ECG in men without clinical evidence of definite IHD is to some extent a marker of underlying heart disease, including coronary artery disease. Moreover, in many studies, the presence of ischemic changes in the resting (ECG), that is, ST-segment depression and T-wave inversion, has been reported to be a strong predictor of fatal IHD in men without clinical evidence of IHD, independent of major conventional risk factors of IHD (Sigurdsson et al.,1996). On studying the resting ECG of our study population, IHD manifestations were found among 6 heat- exposed workers out of the exposed $(n=29)$ ( $20.6 \%$ ) versus 4 out of the control subjects $(\mathrm{n}=29)(13.7 \%)($ table $2 \mathrm{P}<0.05)$. These results are supported by the study of wild et al., (1995) who found higher incidence of IHD among potash miners employed in hot environment. In another Egyptian study, El- Far et al., (1999) reported significantly higher ischemic manifestations in resting ECG in heat-exposed workers in steel industry. Recently, El-Safty et al., (2008) found results comparable to ours among workers in hot areas in glass industry.

Age, smoking, hypertension, diabetes and dyslipidemia are all major risk factors for IHD ( Leon and Bronas, 2009). As mentioned before, both exposed and control groups were matched as regards age, smoking index and fasting blood sugar. Measurement of blood pressure showed lower systolic and diastolic blood pressure values in heat-exposed workers however, there was only one heat-exposed worker who had hypertension in addition to 3 control individuals. This goes in accordance to Chen et al.,(2003) who stated that, low blood pressure is characteristic of high-heat-exposed workers. This can be due to the simultaneous decrease in blood pressure in response to the dilatation of skin vessels to dissipate over-heat (Morioka 
et al., 2006). However, this condition of hypotension is controlled by the role played by members of HSP 70 which was found to enhance the sensitivity of sympathetic and parasympathetic arms of the autonomic nervous system to attenuate heat strokeinduced cerebral ischemia and hypotension (Horowitz and Robinson, 2007).

As regards dyslipidemia, there was a higher percentage of subjects with abnormal lipid profile among the heat-exposed group accompanied with significant increase in mean levels of all lipid profile parameters among this group compared to their controls ( tables 2, $3 \mathrm{P}<0.05$ ). This increase in $\mathrm{TC}$, LDL-C, TC/HDL-C and TG was positively correlated with duration of work and age ( table 4). These findings are greatly supported by the study of Yamamoto et al., (2003) who reported significant increase in total cholesterol levels and HDL-C after exposure to heat and this increase was independent of physical characteristics of the subjects. Moreover, our results go in accordance with 2 studies made by Vangelova et al., ( 2006) and (2007) who found significant increase in TC, HDL-C, LDL-C , TC/HDL-C and TG among workers in hot environments. Although the precise mechanism of induction of lipid synthesis in response to heat exposure remains to be clarified, increase in the secretion rates of cortisol and chatecholamines under overheat may play a role in the heat- related dyslipidemia (vangelova et al., 2002).

Further analysis of the results using ANOVA test (table 5) showed, higher levels of TC, LDL-C and TG among heat-exposed workers having ECG evidence of IHD compared to those having no evidence of IHD. Although HDL-C is apparently higher in heat-exposed group, the TC/HDL-C ratio is also significantly higher as indication of relatively lower HDL-C. As a component of metabolic syndrome, high TG / low HDL-C is an important risk factor because this lipid profile is closely associated with a series of atherogenic and thrombogenic changes all believed to play a central role in the pathogenesis of IHD (Jeppesen et al.,2003). These results indicate that dyslipidemia induced by working under hot environmental conditions, can be the factor behind the increasing prevalence of CVD among heat-exposed workers.

On the other hand, HSP 70 was found to be lower among workers having IHD which goes in accordance with Zhu and his co-workers ( 2003) who reported lower risk of IHD among individuals having higher HSP70 (median level in their work was $50 \mathrm{ng} / \mathrm{dL}$, which is nearly the same 
median level in our study $51.3 \mathrm{ng} / \mathrm{dl}$ ). However, the association between the low risk of IHD and HSP 70 can be due to its multiple intracellular protective effects on a cell's response to stress (Pockely, 2002). Moreover, it is suggested that circulating HSP70 has atheroprotective effects. It is internalised by human endothelial cell populations and this mechanism might be involved in the apparent atheroprotective properties of this protein ( Pockely et al., 2009). Suzuki et al., (2002) demonstrated that HSP72 (a major protein in HSP70 family) enhances manganese superoxide dismutase activity. This enzyme preserves mitochondrial function and limits mitochondrial-related apoptosis during myocardial ischemia.

It is worth noting that, HSP70 expression declines with age (Gray et al., 2000) as it was evident in our study by the negative correlation, though not significant, $(\mathrm{P}>0.05$ table 4), between HSP70 and age (table 4 $\mathrm{P}<0.05)$. This is due to decreased binding of the heat shock factor 1 (HSF-1) to the heat shock element (HSE) and diminished HSP70 transcription. These changes may be associated with decreased thermotolerance upon aging, although HSP70 production in response to other stressors is not affected (Horowitz and Robinson, 2007). On the other hand, the increased prevalence of IHD among elderly heat-exposed workers in our study ( table 5), can be a reflection to the decline of HSP 70 level with age which subsequently diminished its cardioprotective role.

Summing up, our data suggest that the long-term work in hot environment is associated with greater chance of being dyslipidemic. These unfavorable changes in serum lipids are related to the possibility of developing IHD. Besides, our data point to the protective role of HSP 70 in IHD noting that HSP 70 declines with age which necessitate the removal of old age workers from hot work environment to decrease the likelihood of having CVDs and their consequences.

\section{References}

1. Awahl S., Norman J. and Brebner J. 2000: Heat cramps in a hot desert work-site. Kuwait Med. J 32: 382-6.

2. Bates G. and Miller V. 2008: Sweat rate and sodium loss during work in the heat. J Occup. Med. Tox. 3: 432-7

3. Brake D. and Bates G. 2003: fluid losses and hydration status of industrial workers under thermal stress working extended shifts. Occup. Environ. Med. 60: 90-96

4. Chen M., Chen C., Yeh W., Huang J. and Mao I. 2003: Heat stress evaluation and workers fatigue in a steel plant. AIHA. $64: 352-9$

5. El safty A., Salem M., Abdel-Maksoud N. and Helal S. 2008: Cardiovascular manifestations in glass industry. Eg. J.Occup. Med. 32:239-251. 
6. Elfar H., Abdel-Bary A., Salem S. and Ismail A. 1999: Cardiovascular and electrolyte disturbances due to heat exposure among workers in iron and steel industry. Egypt J.Occup. Med. 23:69-79.

7. El-Said K., El- Sharkawy M. and Abdel-Hamid H. 2003: Biochemical changes and environmental factors in manual and semiautomatic bakeries. J.Egypt. Public Health Assoc.78:95-111

8. Epstein Y. and Moran D. 2006: Thermal comfort and the heat stress indices. Ind. Health. 44:388-98.

9. Ghayour-Mobarhan M., Livingstone C., Wang T. and Ferns G. 2005: Plasma antibody titres to heat shock proteins-60, -65 and-70: their relationship to coronary risk factors in dyslipidaemic patients and healthy individuals. Scand. J. Clin. Lab. Invest. 65:601-14.

10. Gomes J., Lloyd O. and Norman N. 2002: The health of the workers in a rapidly developing country: effects of occupational exposure to noise and heat. Occup. Med. 52: 121-8.

11. Gray C., Amrani M., Smolenski R., Taylor G. and Yacoub M. 2000: Age dependence of heat stress mediated cardioprotection. Ann. Thoracic Surgery $70: 621-6$

12. Hancock P. and Vasmatzidis I. 2003: Effects of heat stress on cognitive performance: the current state of knowledge. Int. J. Hyperthermia, 19:355-360

13. Horowitz M. and Robinson S. 2007: Heat shock proteins and the heat shock response during hyperthermia and its modulation by altered physiological conditions. Prog Brain Res. 162:433-46

14. Jeppesen J., Hein H. and Suadicani P. 2003: High Triglycerides/Low High-Density Lipoprotein Cholesterol, Ischemic Electrocardiogram Changes, and Risk of Ischemic Heart Disease. Am. Heart J. 145: 123-133.

15. Kumar Y., Chawla A. and Tatu U. 2003: Heat shock protein 70 as a biomarker of heat stress in a simulated hot cockpit. Aviat Space Environ Med. 74:711-6.

16. Leon S. and Bronas G. 2009: Dyslipidemia and risk of coronary heart disease: role of life style approaches for its management. Am. J life style Med. 3: 257-273

17. Lepore D., Knight K., Anderson R. and Morrison W. 2001: Role of priming stresses and HSP70 in protection from ischemia-reperfusion injury in cardiac and skeletal muscle.Cell Stress Chaperones. 6:93-6.

18. Lim C., Chung K. and Hock L. 1996: The effects of prolonged heat exposure and basic military training on thermo-regulatory and cardiovascular responses in recruits from a tropical country. Mil.Med.162:623-7.

19. Luc H., Richard S., Frans C., Robert VN. and Ger J. 2001: Heat shock proteins and Cardiovascular Pathophysiology. Physiol. Rev. 81: 1461-97

20. Miranda C., Lehmann K. and Froehlicher V. 1991: Correlation between resting ST segment depression, exercise testing, coronary angiography, and long-term prognosis. Am Heart J 122:1617-25.

21. Morioka I., Miyai N. and Miyashita K. 2006: Hot environment and health problems of outdoor workers at a construction site. Ind. Health 44:474-80

22. Narwot T., Staessen J., Fagard R. and StruijkerBoudier H. 2005: Endothelial function and outdoor temperature. Eur. J.Epidemol. 20:407-10

23. Pockley A. 2002: Heat shock proteins, inflammation, and cardiovascular disease. Circulation. 105:1012-17.

24. Pockley A., Calderwood S., and Multhoff G. 2009: The atheroprotective properties of HSP70: a role for HSP70-endothelial interactions? Cell Stress Chaperones. 14:545-53.

25. Rodahl K. 2003: Occupational health conditions in extreme environments. Ann. Occ. Hyg, 47:241-5 
26. Sigurdsson E., Sigfusson N. and Sigvaldason H. 1996: Silent ST-T changes in an epidemiologic cohort study: a marker of hypertension or coronary heart disease, or both: the Reykjavik Study. J. Am. Coll. Cardiol. 27:1140-7.

27. Srivastava A., Kumar R., Joseph E. and Kumar A. 2000: Heat exposure study in the workplace in a glass manufacturing unit in India. Occup. Hyg. 4:449-53.

28. Steinmann C. and Bornman L.1996: Acclimatization, preconditioning and heat shock proteins. Med Hypotheses. 47:257-60.

29. Suzuki K., Murtuza B., Sammut I., Latif N., Jayakumar J., Smolenski R. 2002: Heat shock protein 72 enhances manganese superoxide dismutase activity during myocardial ischemia-reperfusion injury, associated with mitochondrial protection and apoptosis reduction. Circulation. 106(suppl I):270-76.

30. Tanaka M. 2007: Heat stress standard for hot work environment in Japan. Ind. Health 45:8590

31. Vangelova K. and Deyanov C. 1999: Cardiovascular risk in men exposed to overheat. Ann. Scient. Papers. 5:111-2

32. Vangelova K. and Deyanov C. 2007: Blood pressure and serum lipids in industrial workers under intense noise and a hot environment. Rev Environ Health. 22:303-11.

33. Vangelova K., Deyanov C. and Ivanova M. 2002: The effect of heat exposure on cortisol and catecholamines excretion rates in workers in glass manufacturing unit. Cet. Eur. J. Publ. Health $10: 149-52$

34. Vangelova K., Deyanov C. and Ivanova M. 2006: Dyslipidemia in industrial workers in hot environments. Cet. Eur. J. Pub. Health 14:15-17

35. Wild P., Moulin J., Ley F. and Schaffer P. 1995: Mortality from cardiovascular diseases among potash miners exposed to heat. Epidemiol. 6:243-7.

36. Yamamoto H., Zheng K, and Ariizumi M. 2003 : Influence of heat exposure on serum lipid and lipoprotein cholesterol in young male subjects. Ind Health. 41:1-7.

37. Yuan J., Yang M., Yao H., Zheng J., Yang Q., Chen S. 2005: plasma antibodies to heat shock protein 60 and heat shock protein 70 are associated with increased risk of electrocardiograph abnormalities in automobile workers exposed to noise. Cell Stress Chaperones.10:126-135

38. Zhao Y., Wang W. and Qian L. 2007 : HSP70 may protect cardiomyocytes from stress-induced injury by inhibiting Fas-mediated apoptosis. Cell Stress Chaperones. 12: 83-95

39. Zhu J., Quyyumi A., Wu H., Csako G., Rott D., Zalles-Ganley A. 2003: Increased serum levels of heat shock protein 70 are associated with low risk of coronary artery disease. Arterioscler Thromb Vasc Biol. 23:1055-9. 